\title{
Amphotericin Product
}

National Cancer Institute

\section{Source}

National Cancer Institute. Amphotericin Product. NCI Thesaurus. Code C124792.

Any formulation containing amphotericin B as the active agent for the treatment of fungal infections. 